\title{
Nutrients Composition of Some Traditional Soups Consumed By Postpartum Mothers In Nigeria
}

\author{
Mustapha, R.A. \\ Department of Nutrition and Dietetics, Rufus Giwa Polytechnic, PMB 1019, Owo, Ondo State, Nigeria.
}

\begin{abstract}
The proximate and nutrient composition of three selected plants (Crongromena ratifolia, Adansonia digitata and Syzygium aromaticum) used for traditional postpartum soups consumed in West, East and Northern Nigeria by postpartum mothers were prepared and evaluated. Samples were evaluated for their proximate, vitamins and iron content using modified AOAC methods. Finding shows that virtually all the soups have high amount of fat ranging from 43.7-53.5\% per 100g. Carbohydrate was low, however energy values of soups range from 526.6-623.5kcal/100g samples. Although Nsala and Miyan kuka soups have the highest protein (30.85\%)

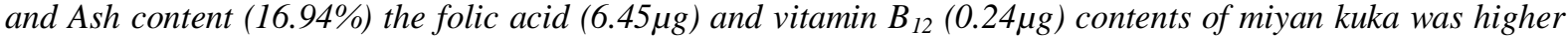
than the other two soups. All soups contain appreciable amount of B-complex while Nsala soup had very high amounts of iron (10.8mg/100g sample) meeting over $80 \%$ of iron need of the mothers. The fat soluble vitamins were present in appreciable amount while all the soups had little or trace amount of vitamin C. Selected traditional soups consumed by postpartum mothers in Nigeria are good sources of vitamins, iron, fat, protein and fibre. Therefore, mothers particularly urban women should be encouraged to eat these traditional soups for both nutritional and therapeutic properties that aid quick recovery from postpartum blood loss and other disorders.
\end{abstract}

Keywords: Traditional soups, Postpartum, Mothers, Nutrients

\section{Introduction}

Postpartum is the period of time following the birth of the baby. It is the time the mother's body is changing to the non-pregnant state. It lasts approximately 6 weeks or until the reproductive organs and other physiological state of the mother returns to their normal state ${ }^{(10)}$. It is a period which begins after delivery of the baby and ends when the mother's body has returned as closely as possible to its pre-pregnant state ${ }^{(12)(6)}$.

The common health problems to new mothers during 6-7 months postpartum are tiredness/exhaustion, backache, pain in perineum or lower uterine caesarian section (LUCS), wound, sexual problems, hemorrhoids, relationship with partner, bowel problems, urinary incontinence, contraception, more upper respiratory tract infections than usual and mastitis ${ }^{(7)}$.

In Nigeria and many developing countries of the world, the common postpartum practices include: sexual abstinence, hot ritual baths, physical confinement, nursing in heated rooms, ingestion of gruel enriched with local salt, medical herbal preparation for bathing and drinking special soups and foods. Mothers believed that these practices made them stronger and helped them regain physiological state. Women are still holding onto postpartum cultural beliefs and practices in Nigeria ${ }^{(17)}$.

The postpartum diet therapy has gained some popularity among the rural peasant people due to its effects on maternal health as well as on the health of the newborn since bioactive substances pass from mother to baby through lactation ${ }^{(4)}$. A vast of medicinal plants available in tropical countries particularly in Nigeria are used for food medicinal purposes. Chukwuma ${ }^{(2)}$ reported that eating more bitter leaf soup could be the panacea for safe childbirth and quick recovery for postpartum women. The root and the leaves decoction of bitter leaf has also been shown to increase uterine contraction and motility for safer childbirth. It is traditionally used in Western Uganda to treat various ailments such as treatment of painful uterus including uterine contractions, management of retained placenta and postpartum bleeding.

Postpartum maternal health care influences the health of both the mothers and their children greatly. Postpartum health care typically provided during the first weeks period after birth is very important to the mother's health. In developing countries over $60 \%$ of maternal death occurs during the postpartum period. Effective postpartum is essential to maximize survival of mothers and newborns regardless of where the women deliver ${ }^{(19)}$.

Caring for the mothers in a loving way will help restore strength, muscle tone, mental clarity and overall sense of wellbeing. Eating well is essential to the recovery of a mother during her postpartum period. Best foods that are good for recovering mothers are those that have high vitamins and mineral contents including whole grain, cooked greens, root vegetables and clean water ${ }^{(3)}$.

Postpartum women are traditionally advised to follow a special dietary pattern, which is quite different from the dietary and lifestyles pattern they maintain before and after this period ${ }^{(6)}$. 
In Nigeria, ignorance, lack of adequate feeding and cultural beliefs of the family or communities have contributed to maternal malnutrition. Information on the nutrients potentials of traditional postpartum soups in Nigeria is minimal and inadequate. Therefore, this study examines the nutrient composition of some traditional soups consumed by postpartum mothers in the West Aaru (Syzygium aromaticum petals), East Ofe Nsala (Crongromena ratifolia, utazi leaves) and Northern Miyan kuka (Adansonia digitata leaves) parts of Nigeria.

\section{Materials And Methods}

Sample Preparation and Procurement

Ingredients used were purchased from various local markets within and outside Ondo State, Nigeria.

The Nsala herbs (Crongromena ratifolia), Kuka leaves (Adansonia digitata), and the Aaru (Syzygium aromaticum) petals were dried and grinded into powdery form, making them ready to prepare into soups.

\section{Method used to Prepare Miyan Kuka}

Ingredients: A pinch of salt, dried pepper, water, oil, yaji, magi, dawadawa, beef and kuka.

- The beef was cut into moderate sizes, the pepper was grinded using traditional stone. The beef was cooked until tender.

- Dried fish was washed using hot water in order to remove the dirt.

- A well washed and cleaned pot was put on the fire, water was added to it and allowed to boil.

- Dried fish, grinded pepper, yaji were added to the boiled water and cooked for 10 minutes. Then dawadawa was added, 2 cubes of magi and a pinch of salt, boiled meat and palm oil was added and stirred very well.

- The grinded kuka leaves were added to the pot on fire, then stirred continuously to avoid lumps and the fire was put off. The $k u k a$ soup was ready to serve.

\section{Method used to Cook Ofe Nsala Soup}

Ingredients: Fresh fish, crayfish, grinded pepper, magi, water, salt, powdered corn meal (thickener), meat.

- Water was added to pot and put on the fire.

- Nsala herbs were added to the water on the fire and allowed to boil for 15 minutes. The herbs were removed from the water, and the boiled water (stock) was used to prepare the soup.

- The fish was washed properly, removed bones and cut them into small sizes and added to the boiled water with cooked meat. It was allowed to boil for some minutes.

- Other ingredients like magi, salt, ground pepper were added and stirred for some minutes.

- Powdered corn meal was added to the soup as thickener.

- The soup was allowed to simmer for 10 minutes on the fire and dropped to be served.

\section{Method used to Prepare Aaru Soup}

Ingredients: Meat, dreid fish, crayfish, magi, salt, palm oil, diced onions, melon seed, water, pepper (grinded), sliced onions.

- The melon seed was grinded using dry blender. Meat was cooked, dried fish was washed using hot water so as to remove the dirt.

- Palm oil was heated on the fire in a cooking pot; the blended pepper was added to the heated oil and fried with sliced onions.

- Crayfish, blended egusi (melon) was added and continue to fry, while stirring it to avoid burning. The cooked meat was added with the spices and seasonings and stirred continuously. The dried fish was added so as to allow the spices soak in.

- Water was added together with the stock and stirred properly. It was allowed to cook for some minutes, then the Aaru was added, then steamed for about 5 minutes and dropped from the fire.

\section{Chemical Analysis}

The proximate compositions of the three soups were determined using the method of AOAC ${ }^{(1)}$. Except the carbohydrate content which was obtained by difference. Iron content of the soups was determined using the method described by AOAC ${ }^{(1)}$.

\section{Statistical Analysis}

Proximate values were determined in triplicate and means and standard deviation were calculated for all the values using procedures of Steel and Torrie ${ }^{(13)}$. 
Results

\section{Results And Discussion}

Table 1: The proximate composition of 3 selected traditional soups consumed by postpartum mothers in Nigeria.

\begin{tabular}{llllllll}
\hline Sample & \% Moisture & \%Ash & \%Fat & \%Fibre & \%Protein & \% CHO & $\begin{array}{l}\text { Energy } \\
\text { (kcal) }\end{array}$ \\
\hline & & & & & & & \\
Aaru soup & $2.71 \pm 0.02$ & $6.73 \pm 0.12$ & $53.57 \pm 1.22$ & $1.64 \pm 0.01$ & $28.67 \pm 1.23$ & $6.68 \pm 0.38$ & $623.53 \pm 5.11$ \\
Nsala soup & $3.86 \pm 0.01$ & $10.72 \pm 0.1$ & $50.01 \pm 3.12$ & $1.71 \pm 0.01$ & $30.85 \pm 2.01$ & $2.85 \pm 0.66$ & $584.89 \pm 8.14$ \\
& & 1 & & & & & \\
Miyan & $4.40 \pm 0.03$ & $16.94 \pm 0.8$ & $43.77 \pm 1.04$ & $1.70 \pm 0.01$ & $23.37 \pm 0.94$ & $9.82 \pm 0.84$ & $526.69 \pm 9.08$ \\
kuka & & 2 & & & & & \\
\hline
\end{tabular}

Table 1 above shows the proximate composition of the 3 selected traditional soups consumed by postpartum mothers in Nigeria. The protein content of Nsala soup was the highest (30.85\%). It was followed by Aaru soup with (28.67\%), while Miyan kuka had the lowest (23.37\%). The ash content and fibre content of Aaru was low compared to the other two samples $(6.73 \%$ Ash and $1.64 \%$ fibre). Nsala soup had the highest fibre content $(1.71 \%)$ and lowest carbohydrate content $(2.85 \%)$, while miyan kuka had the highest carbohydrate content $(9.82 \%)$, and highest moisture content $(4.40 \%)$ compared to other two samples.

Table 2: Iron content of 3 selected traditional soups consumed by postpartum mothers in Nigeria.

\begin{tabular}{lc}
\hline Soups & Iron Content $\mathrm{mg} / 100 \mathrm{~g}$ \\
\hline Aaru & $5.00+0.13$ \\
Nsala & $10.50 \pm 1.04$ \\
Kuka & $8.00 \pm 0.23$
\end{tabular}

Table 2 above shows the iron content of the 3 selected traditional soups consumed by postpartum mothers in Nigeria. Nsala soup had the highest concentration of iron $(10.50 \mathrm{mg} / 100 \mathrm{~g})$, this was followed by miyan kuka (8mg/100g), while Aaru soup had the lowest iron content (5mg/100g).

Table 3: Vitamins content of 3 selected traditional soups consumed by postpartum mothers in Nigeria.

\begin{tabular}{|c|c|c|c|}
\hline Vitamins & Aaru soup & Nsala soup & Miyan kuka \\
\hline Thiamin (mg) Vit $\mathrm{B}_{1}$ & $0.030 \pm 0.001$ & $0.027 \pm 0.00$ & $0.031 \pm 0.001$ \\
\hline Riboflavin (mg) Vit $\mathrm{B}_{2}$ & $0.012 \pm 0.001$ & $0.014 \underline{ \pm} 0.00$ & $0.023 \pm 0.000$ \\
\hline Niacin (mg) Vit $B_{3}$ & $4.283 \pm 0.110$ & $3.428 \pm 0.210$ & $4.005 \pm 0.821$ \\
\hline Pantotenic acid (mg) Vit $B_{5}$ & $6.701 \pm 0.020$ & $0.620 \pm 0.023$ & $0.785 \pm 0.012$ \\
\hline Pyridoxine $(\mathrm{mg})$ Vit $\mathrm{B}_{6}$ & $6.036 \pm 0.940$ & $0.620 \pm 0.001$ & $0.046 \pm 0.001$ \\
\hline Folic acid $(\mu \mathrm{g})$ Vit $\mathrm{B}_{9}$ & $5.367 \pm 0.180$ & $5.627 \pm 0.023$ & $6.456 \pm 0.921$ \\
\hline Cyanocobalamin $(\mu \mathrm{g})$ Vit $\mathrm{B}_{12}$ & $0.190 \pm 0.010$ & $0.139 \pm 0.003$ & $0.242 \pm 0.002$ \\
\hline Ascorbic acid, vitamin $\mathrm{C}(\mu \mathrm{g})$ & Trace & Trace & Trace \\
\hline Vitamin A (mg) & $0.007 \pm 0.000$ & $0.005 \pm 0.000$ & $0.006 \pm 0.00$ \\
\hline Vitamin $\mathrm{D}(\mu \mathrm{g})$ & $2.908 \pm 0.021$ & $3.414 \pm 0.312$ & $2.646 \pm 0.311$ \\
\hline Vitamin E (mg) & $0.531 \pm 0.041$ & $0.693 \pm 0.042$ & $0.539 \pm 0.020$ \\
\hline Vitamin $\mathrm{K}(\mu \mathrm{g})$ & $0.849 \pm 0.011$ & $0.101 \pm 0.003$ & $0.119 \pm 0.031$ \\
\hline
\end{tabular}

Table 3 above shows the vitamin content of 3 selected traditional soups consumed by postpartum mothers in Nigeria. Miyan kuka had the highest thiamin content $(0.031 \mathrm{mg})$, while Nsala soup had the lowest thiamin content $(0.027 \mathrm{mg})$. The riboflavin content of the soup samples ranged between $0.012-0.014 \mathrm{mg} / 100 \mathrm{~g}$. Aaru soup was found to have almost the same niacin content with miyan kuka, while the niacin content of Nsala soup is $3.428 \mathrm{mg} / 100 \mathrm{~g}$. Vitamin $\mathrm{B}_{6}$ content was very high in Nsala soup $(0.620 \mathrm{mg})$, followed by miyan kuka $(0.046 \mathrm{mg})$. Miyan kuka had the highest folic acid content $(6.455 \mu \mathrm{g})$, that was followed by Nsala soup $(5.367 \mu \mathrm{g})$. The

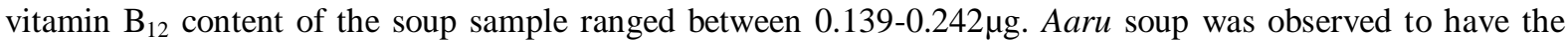
highest vitamin A content $(0.007 \mathrm{mg})$ and Nsala soup had the lowest $(0.05 \mathrm{mg})$. Vitamin D and E content of Nsala soup was the highest among the 3 soup samples. Aaru soup had the highest vitamin K $(0.849 \mu \mathrm{g})$; it was followed by miyan kuka $(0.119 \mathrm{mg})$. There was no much difference between the vitamin $\mathrm{K}$ content of miyan kuka and Nsala soup.

\section{Discussion}

Table 1 shows the proximate composition of 3 selected traditional soups consumed by postpartum mothers in Nigeria. Aaru had the highest percentage of fat $(53.57 \%)$, this may be due to inclusion of melon and 
high amount of palm oil in the soup and other ingredients that are a source of fat. The fat content of Nsala and miyan kuka were also high $(50.01 \%$ and $43.77 \%)$ respectively. This indicates that all the 3 soup samples are good sources of fat and energy.

Ash content of miyan kuka was very high (16.94\%) compared to the other 2 samples. This indicates that the soup contain some amounts of inorganic substances (minerals) necessary for body utilization. Nsala soup had the highest fibre content $(1.71 \%)$, this may be due to melon and herbs used to prepare the soup. Baobab leaves contain appreciable amounts of fibre, this contributes to the increase in the fibre content of miyan $k u k a$ soup. The soups are good for postpartum mothers, because high fibre foods are recommended for postpartum mothers to help prevent postpartum constipation ${ }^{(11)}$. Nsala soup had appreciable amount of protein (30.85\%), this was followed by Aaru soup (23.67\%) while miyan kuka had the lowest (23.37\%). The protein content of all the soups were high, this may be probably due to combination of various ingredients meat, fish and plant materials, which are good sources of protein. The percentage carbohydrate of the soups were low, miyan kuka had the highest carbohydrate content $(9.82 \%)$. This will contribute to energy content of the soup.

Iron plays a vital role in the body, it is a component of red blood cells. The metabolic roles of minerals and the amount of them in the body vary considerably ${ }^{(15)}$. Iron deficiency anaemia has been reported to be extremely common in the developing world among postpartum women ${ }^{(14)}$. Nsala soup had the highest level of iron $(10.5 \mathrm{mg})$. This may be due to the nutrients contained in the various combination of herbs used in the soup preparation which are a source of iron ${ }^{(5)}$. Miyan kuka had appreciable amount of iron of $8.00 \mathrm{mg} / 100 \mathrm{~g}$, while Aaru soup also contained iron content of $5 \mathrm{mg} / 100 \mathrm{~g}$. This higher amount of iron in these food samples may be due to combinations of assorted meats, fish and other ingredients added to the soups. The RDA for iron during postpartum is between $11-27 \mathrm{mg} / \mathrm{day}^{(18)}$. This indicates that the selected traditional soups will be able to supply more than half of the daily dietary needs for iron for these women.

Folic acid (vitamin $\mathrm{B}_{9}$ ) is needed for the synthesis of essential components of DNA and RNA which increase rapidly during growth, thereby increasing the requirements of folic acid during postpartum because of blood loss during delivery, lack of dietary folic acid leads to folate deficiency ${ }^{(14)}$. Miyan kuka had appreciable amount of folic acid $(6.456 \mu \mathrm{g})$ compared to the other two samples Nsala and Aaru soups which had 5.627 $\mu \mathrm{g}$ and $5.367 \mu \mathrm{g}$ respectively. RDA for folic acid during lactation is $150 \mu \mathrm{g} / \mathrm{day}{ }^{(8)}$. Moreover, the soups contain low amount of folic acid, this makes supplementation very important. Besides the soups are consumed with other foods like leafy vegetables, beans, cereals which could supply some amount of folate in order to meet their daily dietary needs. Vitamin $B_{12}$ is involved in biochemical processes essential for DNA synthesis and therefore, for the growth and division of cells ${ }^{(14)}$. Miyan kuka had the highest vitamin $B_{12}$ content $(0.242 \mu \mathrm{g})$. The vitamin b12 content of the other two samples ranged from $0.13 \mu \mathrm{g}$ to $0.190 \mu \mathrm{g}$. RDA for vitamin $\mathrm{B}_{12}$ during postpartum is $1.5 \mathrm{~g} / \mu$ day, this indicates that the soups are good sources of vitamin $\mathrm{B}_{12}$; this may be due to inclusion of meat, fish and other ingredients used to prepare the soups.

Vitamin A content of Nsala soup was lower than the other two samples. Although, ingredients such as meat, fish, corn flour as thickener were used but vegetable oil was not added to the soup. This may be one of the reason for low vitamin A content of the soup. Moreso, herbs used in preparation of this soup has been subjected to sundrying. Exposure of leaves to sunlight destroys Beta-carotene ${ }^{(14)}$. Niacin content of the soup samples were also high, this may be because of inclusion of meat which is a good source of niacin to the soups. RDA for niacin during 0-6 months postpartum is $+2 \mathrm{mg} / \mathrm{day}$, this indicates that the soups will be able to meet the daily dietary needs of mothers. Nsala soup had the highest vitamin D and E content with $3.414 \mu \mathrm{g}$ and $0.693 \mathrm{mg}$ respectively. The increase in the vitamin E content may probably be as a result of corn flour used as thickener in the preparation of the soups as reported by Srillakshimi, ${ }^{(14)}$.

Aaru soup had the highest vitamin K, this may be due to meat and other assorted fishes, used to prepare the soup. It is reported that concentration of vitamin $\mathrm{K}$ is high in fish and meat products ${ }^{(14)}$. Nsala and Miyan kuka contained almost the same amount of vitamin K $0.101 \mu \mathrm{g}$ and $0.119 \mu \mathrm{g}$ respectively. ${ }^{(14)}$. The vitamin $\mathrm{C}$ content of soups were trace, this may be due to loss of vitamin C during drying of the soups, on exposure to sunlight. The soups were subjected to long time of cooking, cooking destroys vitamin C rapidly because it is very unstable in the presence of heat ${ }^{(16)}$. Thiamin serves as a co-enzyme of carbohydrate metabolism. Nsala soup had the lowest thiamin content $(0.027 \mathrm{mg})$ compared to other two samples. Riboflavin is a relatively stable vitamin that is resistant to acid, heat and oxidation. Miyan kuka had the highest riboflavin content $(0.023 \mathrm{mg})$ compared to other two samples. It was stated that Baobab leaves contain good amount of vitamins, especially riboflavin, the tender leaves contain more riboflavin than the mature ones ${ }^{(9)}$. The main ingredient of Miyan kuka is baobab leaves, this may be the reason why its niacin content was the highest. Aaru soup had the lowest vitamin $\mathrm{B}_{6}$ $(0.036 \mathrm{mg})$ and Miyan kuka had the highest vitamin $\mathrm{B}_{5}$, while Nsala soup had the highest vitamin $\mathrm{B}_{6}$.

\section{Conclusion}

This study was conducted to determine the nutrients composition of traditional soups (Ofe Nsala, Miyan kuka and Aaru) consumed by postpartum mothers in Nigeria. The study has established that the selected 
traditional soups consumed by postpartum mothers are good sources of vitamins, iron, fat, protein and fibre. The soups are usually combined with other foods like pounded yam, yam flour, tuwo shinkafa, thereby increasing the macronutrients content in the diet. Therefore, women should eat foods such as fruits and vegetables that are rich in iron, folic acid and vitamin $\mathrm{B}_{12}$, in order to aid quick recovery from postpartum blood loss. Therefore, mothers particularly urban women should be encouraged to eat these traditional soups for both nutritional and medicinal therapeutic properties that aid quick recovery from postpartum stress and blood loss.

\section{References}

[1] AOAC (1990). Official methods of Analysis of the Association of Official Analytical Chemistry, AOAC, Washington DC

[2] Chukwuma, S.L. (2008). Special traditional postpartum foods. Herbal remedies for postpartum women. Quarterly Journal of Hospital Medicine, 18:137-141.

[3] De Brouwere (1998). Strategies for reducing maternal mortality in developing countries. Tropical medicine and International Health, volume 3:777-78

[4] Jain N., Neelan J., Sharma V., and Ramawat K. (2011). Therapeutic potentials of medicinal plants traditionally used during postpartum period and their molecular targets. Journal of Ecobiotechnology 3(10):30-39

[5] Kayode O.F., Ozumba A.U., Ojeniyi S., Adetuyi D.O. and Erukainwe O.L. (2010). Micronutrient content of selected indigenous soups in Nigeria. Pakistan Journal of Nutrition, 9(10):962-965

[6] Liu N., Muo L., Sun X.F., Liu L.G., Chen B.H. and Ding Q. (2006). Postpartum practices of puerperal women and their influencing factors in 3 regions of Hubei, China. BMC public health. 6:274

[7] Miller L., and Milman S.L. (1999). Postpartum mood disorders. American

[8] psychiatric press. Journal of American Medical Association, 274(6):420-308. National Institute of Nutrition (2000). Nutrients requirements for pregnancy and postpartum mothers. Journal of Women health and Gender Based Medicine, 10(10):983-989

[9] Nurdeide G.S. and Laden P. (1995). Evaluation of antinutrient properties of medicinal plants used in diet therapy during postpartum healthcare in Nigeria. Journal of Pharmacy and Pharmaceutical Sciences, 4:128-132

[10] Parry L., Forbes G. and Specker B.L. (2001). Postpartum HEALTH AND CARE: Importance of postpartu m care to mother and child. Asian Journal of Clinical Nutrition, 2:12-22

[11] Payton R.G. and White P. (1995). Primary care for postpartum women: Assessment of hematologic disorders. Journal of Nutrition,73(2):121-32

[12] Pritchard, S.L. (2002). Postpartum cultural beliefs and practices in Nigeria. Journal of Nutrition, 02:105

[13] Srillakshimi, B. (2008). Nutrition Science. $6^{\text {th }}$ ed. New Age International Ltd., India.

[14] Steel R.G.D. and Torrie J.H. (1960). Principles and Procedures of Statistics. McGraw Hill Book, London.

[15] Wardlaw, G.M. (1999). Perspectives in Nutrition, $4^{\text {th }}$ Ed. Mc Graw Hills, Boston, 228-231

[16] Wardlaw, G.M. (2006). Contemporary Nutrition. Sixth edition. Mc Graw Hills, Boston, 288-291

[17] WHO (2001). Postpartum care of the mother and newborn. Report of a technical group. Geneva.

[18] WHO and FAO (2003). Recommended Dietary Allowance for pregnant and lactating women. A report of the Expert group of World Health Organization, and Food and Agriculture Organization.

[19] WHO and UNICEF (2010). Taking stock of maternal and newborn survival. American Journal of Maternal and Child Nursing, 26:7375 